\title{
Refletindo sobre Administração Contemporânea
}

\author{
Reflecting on Contemporary Administration
}

Marcelo de Souza Bispo*1,2

\section{PREÂMBULO}

Neste primeiro editorial da Revista de Administração Contemporânea (RAC) sob a minha gestão, gostaria de, primeiramente, manifestar a minha alegria e motivação para dar continuidade ao trabalho científico e editorial da revista que já está próximo de completar 25 anos. Agradeço pela confiança da atual diretoria da ANPAD (2021-2024) e a todos os editores que me antecederam (Clóvis Luiz Machado-da-Silva, César Gonçalves Neto, Tomas de Aquino Guimarães, Rogério Hermida Quintella, Herbert Kimura e Wesley Mendes-da-Silva) por suas contribuições oferecidas à RAC de modo que ela pudesse chegar ao patamar de excelência em que se encontra hoje. Espero estar à altura (juntamente com toda a equipe editorial) para que a RAC continue sendo referência nacional e avance ainda mais internacionalmente no campo da administraçáo. Estou ciente das responsabilidades e desafios que temos pela frente.

Feitos os agradecimentos iniciais, pretendo, neste texto, apresentar algumas reflexōes acerca do que representa a ideia de 'administração contemporânea'. Tal iniciativa parte de uma demanda da atual direçáo da ANPAD em definir focos e escopos mais claros para as revistas da associação, a RAC e a BAR - Brazilian Administration Review, com a ajuda de um grupo de trabalho formado por pessoas com ampla experiência científica e editorial.

* Autor Correspondente.

1. Universidade Federal da Paraiba, Programa de Pós-Graduação em Administração, João Pessoa, PB, Brasil. 2. Editor-chefe da RAC - Revista de Administração Contemporânea.
Como meio de oferecer à RAC foco e escopo que consigam diferenciá-la da BAR, o grupo de trabalho e os atuais editores associados da RAC definiram que a ideia de 'contemporâneo' é o melhor caminho para justificar o nome da revista e honrar a sua trajetória ao longo de quase duas décadas e meia. Entretanto, ao mesmo tempo que a palavra 'contemporâneo' parece ser muito adequada para pensar a administração e ser supostamente conhecida por todo o público da RAC, apresentar um entendimento adequado para ela é algo complexo e necessário.

Nesse sentido, apresento dois pressupostos que vão ajudar no desenvolvimento das ideias que seguem na sequência. $O$ primeiro deles é que 'contemporâneo' não se refere à simples definição de dicionário de algo que pertence ao tempo atual ou ainda de algo que existiu em uma mesma época. O segundo diz respeito à amplitude de possibilidades do contemporâneo, ou seja, ao mesmo tempo que é possível pensar pesquisas de todas as áreas de forma contemporânea, nem tudo cabe dentro do escopo da RAC. Tendo em perspectiva esses dois pressupostos, ofereço uma reflexáo sobre o que podemos pensar como 'contemporâneo'. A proposta é refletir sobre a concepçáo de 'administração contemporânea' que a RAC pretende debater junto ao meio acadêmico e à sociedade de maneira mais ampla. 


\section{SOBRE A NOÇÃO DO QUE VEM A SER CONTEMPORÂNEO}

O entendimento de que o 'contemporâneo' é tudo aquilo que se refere ao tempo presente é muito comum em diversos contextos, inclusive o acadêmico. É recorrente o uso dessa palavra sem problematizá-la como se fosse dada (taken for granted). A minha ideia aqui não é monopolizar o entendimento e o uso geral da palavra 'contemporâneo', mas de oferecer uma perspectiva que reflita um conceito que está alinhado com o foco e o escopo da RAC. Assim, o contemporâneo tem a ver com a condição que pessoas têm de aprender o seu tempo sendo capazes de realizar aproximaçóes e distanciamentos em relação a ele (Agamben, 2009). Quem está muito preso ao contemporâneo não consegue interpretá-lo, justamente pela falta de capacidade de se descolar dele, ou seja, de estranhá-lo para depois conhecê-lo e refletir sobre ele. O contemporâneo é sempre resultado de um processo histórico que nos ajuda a (re) conhecer o presente. "O que nos torna contemporâneos, então, não é a condição temporal do presente, mas a atualidade de uma questáo que nos implica enquanto atores das práticas que paradoxalmente se inscrevem em nossos tecidos" (Pacheco, 2010, p. 88). O contemporâneo não está atrelado, exclusivamente, ao tempo presente, mas tem a ver com um "regime de identificação" que nos permite perceber temas relevantes para o mundo atual (Rancière, 2005, p. 28). O contemporâneo traz em seu bojo um "conjunto de questóes que permanecem relevantes para o melhor entendimento das pessoas e do contexto sócio-estético-político em que atuam, criam, pensam e transformam" (Almeida, 2012, p. 73).

\section{ADMINISTRAÇÃO CONTEMPORÂNEA}

Pensar o contemporâneo no contexto da administração vai além de uma questão cronológica do presente. Ela deve caminhar no sentido de reconhecer no hoje uma construção histórica que entrelaça passado, presente e futuro e possibilite compreender formas atuais de agir e organizar da sociedade. Mas, ao mesmo tempo, a administração contemporânea deve ser também capaz de reconhecer, refletir e atuar nos temas que se apresentam relevantes no mundo atual. Portanto, a administraçáo contemporânea não se resume ao que acontece no presente e nem deve estar descolada do contexto social do qual ela faz parte. Nesse sentido, a administraçáo contemporânea não pode ser resumida a uma prática individualista $\mathrm{e}$ supostamente 'racional' (Cabantous \& Gond, 2011) que se apresenta como neutra, apolítica e não problemática (Alvesson \& Willmott, 1992). Nem mesmo pode estar orientada exclusivamente para maximização de lucros e bemestar financeiro de uma minoria (Pio \& Waddock, 2021).
A administraçáo contemporânea precisa se engajar em como promover uma relaçáo mais equilibrada entre o mundo dos negócios e a sociedade (Fleming \& Oswick, 2014; Rhodes \& Fleming, 2020; Zanoni, Contu, Healy, \& Mir, 2017).

Uma boa iniciativa para pensarmos o contemporâneo foi a criação dos Objetivos de Desenvolvimento Sustentável da Organização das Nações Unidas (ONU) que apresentam desafios contemporâneos que a sociedade global enfrenta e precisa mitigar. Questôes, por exemplo, relacionadas à pobreza e desigualdade, meio ambiente, educação de qualidade, trabalho decente, consumo responsável, energia limpa, paz e justiça não podem deixar de serem levadas em conta quando fazemos pesquisa em administração contemporânea. Os debates sobre a relação entre teoria e prática (Bispo, 2021; Lundberg, 2004; Van de Ven, 1989), assim como do impacto da pesquisa (Edwards \& Meagher, 2020; Godin \& Doré, 2005; Gunn \& Mintrom, 2017; Sandes-Guimarães \& Hourneaux, 2020), perdem o sentido se não estiverem alinhados coerentemente com os temas relevantes do contemporâneo.

Boa parte do problema levantado sobre uma suposta dicotomia entre 'teoria e prática' (Lundberg, 2004; Van de Ven, 1989) no campo da administração (Bispo, 2021) está, justamente, em como muitos pesquisadores da área ignoram os problemas sociais. Assim, vários conceitos e modelos propostos desconsideram o contexto social e os reais motivos e interesses de vários discursos dominantes (especialmente na área de negócios). Eles distorcem ou 'criam' uma realidade que atende a interesses específicos e são vendidos como bem comum (Dardot \& Laval, 2013; Rhodes \& Fleming, 2020; Zanoni et al., 2017). Se o que fazemos parte de ideias que náo levam em conta o mundo concreto, vivido, como será possível aproximar teoria e prática? Nós da administração costumamos ter certa soberba em achar que sabemos como as coisas devem ser ou funcionar criando modelos que buscam 'enlatar' a realidade (Ghoshal, 2005). É a lógica do 'enlatamento' que transforma uma relação simbiótica em outra dicotômica no que diz respeito a 'teoria e prática'.

Algo semelhante também está presente quando falamos de 'impacto' da pesquisa. É interessante perceber que academicamente assumimos que impacto é bom! Nos esquecemos de problematizar o assunto e de lembrarmos que nenhum impacto é unidirecional (Bispo \& Davel, in press). Ou seja, o que pode ser considerado impacto positivo para alguns, pode ter uma conotação negativa para outros. Há necessidade de avaliação criteriosa das múltiplas consequências do que chamamos de 'impacto'. Precisamos tomar cuidado para que a prática científica não esteja resumida ao que é 'aplicável' e 'útil' para a sociedade, quando, na verdade, a 'sociedade' está resumida a grupos de interesses que buscam legitimar suas intençôes por meio 
de leis e discursos totalizantes sob o argumento de que se trata do 'bem comum' (Godin \& Doré, 2005; Pitman \& Berman, 2009). Cabe lembrar que a definição do que é bom para a sociedade sempre carrega algum grau de controvérsia e polêmica (Gunn \& Mintrom, 2017).

Nesse sentido, pensar impacto na administração contemporânea exige um olhar que vá além da lógica gerencialista (Clegg, 2014; Klikauer, 2013) que se esconde (em geral) dos problemas sociais se apresentando como 'técnica', 'neutra' e 'apolítica'. Ora, existe coesão social e sociedade sem política? Não podemos confundir a gramática político-partidária no Brasil (Nunes, 2010) com o conceito clássico de política (Aristóteles, 1997). A noção política aristotélica busca, justamente, promover a felicidade humana e o bem coletivo. Se realmente quisermos avançar de modo que as nossas pesquisas tenham um impacto positivo, precisamos avaliar os grandes desafios sociais e pensar como a administração contemporânea pode contribuir no enfrentamento deles. É preciso avaliar se o impacto gerado náo atende apenas a interesses de poucos frente ao bem comum. É como defende Almeida (2012): "contemporâneo é, portanto, aquele que consegue ver no presente o que está subentendido, sugerido nas entrelinhas, oculto ou cego pela clareza sedutora e ludibriante do imediato" (Almeida, 2012, p. 80).

\section{ADMINISTRAÇÃO CONTEMPORÂNEA NA RAC}

Diante do que já foi apresentado até aqui, resta comentar de maneira mais específica o que a RAC espera publicar. O foco das publicaçóes na RAC está em responder aos desafios contemporâneos da sociedade com novas possibilidades teóricas, metodológicas e práticas, relacionadas à administração de empresas, organizaçôes públicas ou sociedade civil. Nesse sentido, todas as áreas da administração podem oferecer diferentes olhares e contribuições de como a administração contemporânea pode se associar na produção de conhecimento orientado por questóes éticas, de diversidade, de responsabilidade, de governança e de sustentabilidade que ajudem a construir relações humanas melhores.

Uma maneira de conseguir entender como a administração pode contribuir com as questóes relevantes do contemporâneo é conhecer os Objetivos de Desenvolvimento Sustentável da ONU. A ideia não é vincular nenhum trabalho a algum objetivo específico proposto pela ONU, mas ter em mente o que está sendo considerado como desafiador e importante para o bem-estar global. Trata-se de fazer um exercício reflexivo que leve a uma autocrítica do trabalho realizado. Em outras palavras, a RAC espera que os autores reflitam sobre as seguintes perguntas: $\mathrm{O}$ meu trabalho atende a interesses específicos que não contribuem ou atrapalham a realizaçáo do bem comum? Será que o meu trabalho promove relaçóes precárias de trabalho, impactos negativos ao meio ambiente, desconsidera a diversidade ou coloca o lucro em prioridade face à segurança, à equidade e à justiça social? As respostas a essas perguntas visam a estimular que os trabalhos publicados na RAC estejam alinhados à promoção de conhecimentos que ajudem a sociedade (como um todo) a enfrentar os seus dilemas e desafios.

Que a RAC possa continuar sendo uma revista científica contemporânea apta a fomentar e promover conhecimentos capazes de provocar na área de administração práticas no mundo dos negócios, na administração pública, no terceiro setor ou mesmo na sociedade cível que sejam socialmente responsáveis.

\section{REFERÊNCIAS}

Agamben, G. (2009). O que é o contemporâneo? E outros ensaios (Chap. 3, pp. 52-73). Chapecó, SC: Argos, 2009.

Almeida, E. A. A. (2012). Charles Baudelaire: Contemporâneo do passado, do presente e do futuro. Revista Poiésis, 13(20), 73-84. https://doi.org/10.22409/poiesis.1320.73-84

Alvesson, M., \& Willmott, H. (1992). Critical management studies. London: Sage.

Aristóteles. (1997). Política (3 ed.). Brasília: Editora Universidade de Brasília.
Bispo, M. de S. (2021). Ensaiando sobre o velho e falso dilema entre teoria e prática. Teoria e Prática em Administração, 11(2), 174-178. https://doi.org/10.22478/ufpb.2238$\underline{104 X .2021 \mathrm{v} 11 \mathrm{n} 2.59760}$

Bispo, M. de S., \& Davel, E. P. (in press). Editorial: Impacto educacional da pesquisa. Organizaçóes \& Sociedade, in press.

Cabantous, L., \& Gond, J.-P. (2011). Rational decision making as performative praxis: Explaining rationality's éternel retour. Organization Science, 22(3), 573-586. https://doi.org/10.1287/orsc.1100.0534 
Clegg, S. R. (2014). Managerialism: Born in the USA. Academy of Management Review, 39(4), 566-585. https://doi.org/10.5465/amr.2014.0129

Dardot, P., \& Laval, C. (2013). The new way of the world: On neoliberal society. New York: Verso.

Edwards, D. M., \& Meagher, L. R. (2020). A framework to evaluate the impacts of research on policy and practice: A forestry pilot study. Forest Policy and Economics, 114, 101975. https://doi.org/10.1016/j.forpol.2019.101975

Fleming, P., \& Oswick, C. (2014). Educating consent? A conversation with Noam Chomsky on the university and business school education, Organization, 21(4), 568-578. https://doi.org/10.1177/1350508413514748

Ghoshal, S. (2005). Bad management theories are destroying good management practices. Academy of Management Learning and Education, 4(1), 75-91. https://doi.org/10.5465/amle.2005.16132558

Godin, B., \& Doré, C. (2005). Measuring the impacts of science: Beyond the economic dimension. Helsinki, Finland: Helsinki Institute for Science and Technology Studies. Retrieved from www.csiic.ca/PDF/Godin Dore Impacts.pdf

Gunn, A., \& Mintrom, M. (2017). Evaluating the non-academic impact of academic research: Design considerations. Journal of Higher Education Policy and Management, 39(1), 20-30. https://doi.org/10.1080/1360080X.2016.1254429

Klikauer, T. (2013). Managerialism: A critique of an ideology. New York: Palgrave MacMillan.

Lundberg, C. C. (2004). Is there really nothing so practical as a good theory? Business Horizons, 47(5), 7-14. https://doi.org/10.1016/j.bushor.2004.07.003
Nunes, E. de O. (2010). A gramática politica do Brasil: Clientelismo, corporativismo e insulamento burocrático (4 ed.). Rio de Janeiro: Garamond.

Pacheco, E. M. (2010). Dos poros ao sopro: A dimensão estética da experiência. In E. A. Lima, J. L. Ferreira Neto, L. E. Aragon (Orgs.), Subjetividade contemporânea: Desafios teóricos e metodológicos (Chap. 6, pp. 85-94). Curitiba: Editora CRV.

Pio, E, \& Waddock, S. (2021). Invoking indigenous wisdom for management learning. Management Learning, 52(3), 328346. https://doi.org/10.1177/1350507620963956

Pitman, T., \& Berman, J. E. (2009). Of what benefit and to whom? Linking Australian humanities research with its 'end users'. Journal of Higher Education Policy and Management, 31(4), 315-326. https://doi.org/10.1080/13600800903191955

Rancière, J. (2005). A partilha do sensivel: Estética e política. São Paulo: Editora 34.

Rhodes, C., \& Fleming, P. (2020). Forget political corporate social responsibility. Organization, 27(6), 943-951. https://doi. org/10.1177/1350508420928526

Sandes-Guimarães, L. V., \& Hourneaux, F., Junior. (2020). Research impact - what is it, after all? Editorial impact series part 1. RAUSP Management Journal, 55(3), 283-287. https://doi. org/10.1108/RAUSP-07-2020-202

Van de Ven, A. H. (1989). Nothing is quite so practical as a good theory. Academy of Management Review, 14(4), 486-489. https://doi.org/10.5465/amr.1989.4308370

Zanoni, P., Contu, A., Healy, S., \& Mir, R. (2017). Post-capitalistic politics in the making: The imaginary and praxis of alternative economies. Organization, 24(5), 575-588. https://doi.org/10.1177/1350508417713219 


\section{Autoria}

\section{Marcelo de Souza Bispo*}

Universidade Federal da Paraíba, Programa de Pós-Graduação em Administração.

Campus I, Lot. Cidade Universitaria, 58051-900, João Pessoa, $\mathrm{PB}$, Brasil.

E-mail: rac-eic@anpad.org.br

(D) https://orcid.org/0000-0002-5817-8907

* Autor Correspondente

\section{Conflito de Interesses}

$\mathrm{O}$ autor informou que não há conflito de interesses.

\section{Direitos Autorais}

A RAC detém os direitos autorais deste conteúdo.

\section{Verificação de Plágio}

A RAC mantém a prática de submeter todos os documentos aprovados para publicação à verificação de plágio, mediante o emprego de ferramentas específicas, e.g.: iThenticate.

\section{CORPO EDITORIAL CIENTÍFICO E EQUIPE EDITORIAL PARA ESTA EDIÇÃO:}

\section{Conselho Editorial}

Anielson Barbosa da Silva (UFPB, João Pessoa, PB, Brasil) Antonio Carlos Gastaud Maçada (UFRGS, Porto Alegre, RS, Brasil) Ely Laureano Paiva (FGV, São Paulo, SP, Brasil)

Rogério Hermida Quintella (NPGA/UFBA, Salvador, BA, Brasil) Valmir Emil Hoffmann (UnB, Brasília, DF, Brasil)

\section{Editor-chefe}

Marcelo de Souza Bispo (UFPB, João Pessoa, PB, Brasil)

\section{Editores Associados}

Ariston Azevedo (UFRGS, Porto Alegre, RS, Brasil)

Carolina Andion (UDESC, Florianópolis, SC, Brasil)

Denize Grzybovski (UPF, Passo Fundo, RS, Brasil)

Eduardo da Silva Flores (FEA/USP, São Paulo, SP, Brasil)

Elisa Yoshie Ichikawa (UEM, Maringá, PR, Brasil)

Emílio José M. Arruda Filho (UNAMA, Belém, PA, Brasil)

Fernando Luiz Emerenciano Viana (Unifor, Fortaleza, CE, Brasil)

Gustavo da Silva Motta (UFF, Niterói, RJ, Brasil)

Henrique Castro Martins (IAG/PUC-Rio, Rio de Janeiro, RJ, Brasil)

Keysa Manuela Cunha de Mascena (Unifor, Fortaleza, CE, Brasil)

Ludmila de Vasconcelos Machado Guimarães (CEFET-MG, Belo

Horizonte, MG, Brasil)

Natália Rese (UFPR, Curitiba, PR, Brasil)

Orleans Silva Martins (UFPB, João Pessoa, PB, Brasil)
Pablo Isla Madariaga (Universidad Técnica Federico Santa María, Chile)

Paula Castro Pires de Souza Chimenti (UFRJ/Coppead, Rio de Janeiro, Brasil)

Rafael Chiuzi (University of Toronto Mississauga, Mississauga, ON, Canadá)

Sidnei Vieira Marinho (Univali, São José, SC, Brasil)

\section{Corpo Editorial Científico}

André Luiz Maranhão de Souza-Leão (UFPE, Recife, CE, Brasil)

Aureliano Angel Bressan (CEPEAD/UFMG, Belo Horizonte, MG, Brasil)

Bryan Husted (York University, Canadá)

Carlos M. Rodriguez (Delaware State University, EUA)

Cristiana Cerqueira Leal (Universidade do Minho, Portugal)

Diógenes de Souza Bido (Mackenzie, São Paulo, SP, Brasil)

Erica Piros Kovacs (Kelley School of Business/Indiana University, EUA)

Elin Merethe Oftedal (University of Stavanger, Noruega)

Fábio Frezatti (FEA/USP, São Paulo, SP, Brasil)

Felipe Monteiro (INSEAD Business School, EUA)

Howard J. Rush (University of Brighton, Reino Unido)

James Robert Moon Junior (Georgia Institute of Technology, EUA)

John L. Campbell (University of Georgia, EUA)

José Antônio Puppim de Oliveira (United Nations University, Yokohama, Japão)

Julián Cárdenas (Freie Universität, Berlin, Alemanha)

Lucas A. B. de Campos Barros (FEA/USP, São Paulo, SP, Brasil)

Luciano Rossoni (UniGranRio, Rio de Janeiro, RJ, Brasil)

M. Philippe Protin (Université Grenoble Alpes, França)

Paulo Estevão Cruvinel (Embrapa Instrumentação, São Carlos, SP, Brasil)

Rodrigo Bandeira de Mello (Merrimack College, EUA)

Rodrigo Verdi (MIT Massachusetts Institute of Technology, Cambridge, EUA)

Valter Afonso Vieira (UEM, Maringá, PR, Brasil)

Wagner A. Kamakura (Jones Graduate School of Business, Rice University, Houston, EUA)

\section{Editoração}

Diagramação e normas da APA: Kler Godoy (ANPAD, Maringá, Brasil); Simone L. L. Rafael (ANPAD, Maringá, Brasil).

Periodicidade: Publicação contínua.

Circulação: Acesso totalmente gratuito.

\section{Indexadores, Diretórios e Rankings}

Scielo, Redalyc, DOAJ, Latindex, Cengage/GALE, Econpapers, IDEAS, EBSCO, Proquest, SPELL, Cabell's, Ulrichs, CLASE, Index Copernicus International, Sherpa Romeo, Carhus Plust, Academic Journal Guide (ABS), DIADORIM, REDIB, Sumários.org, ERIHPlus, EZB, OasisBR, IBZ Online, WorldWideScience, Google Scholar, Citefactor.org, MIAR, Capes/Qualis. 